\title{
STRATEGI PEMECAHAN MASALAH MEKANIKA FLUIDA MENURUT TAKSONOMI SOLO
}

\author{
*M. Dewi Manikta \\ Puspitasari \\ Universitas Nusantara PGRI \\ Kediri \\ dewimanikta@gmail.com \\ Kuni Nadliroh \\ Universitas Nusantara PGRI \\ Kediri \\ kuninadliroh@unpkediri.ac.id \\ Muhammad Najibulloh \\ Muzaki \\ Universitas Nusantara PGRI \\ Kediri \\ m.n.muzaki@gmail.com
}

*koresponden author

\begin{abstract}
Abstrak - Tujuan penelitian ini adalah mendeskripsikan strategi pemecahan masalah mahasiswa berkemampuan fisika tinggi dan sedang dalam menyelesaikan soal mekanika fluida. Penelitian ini merupakan penelitian kualitatif. Subjek penelitian adalah mahasiswa yang menempuh mata kuliah mekanika fluida. Pengumpulan data penelitian ini menggunakan wawancara, tes mekanika fluida dan tes kemampuan fisika. Tes kemampuan fisika digunakan untuk mengelompokkan tingkatan kemampuan fisika mahasiswa tinggi dan sedang bedasarkan kriteria nilai hasil tes kemampuan fisika mahasiswa. Sedangkan strategi pemecahan masalah ditentukan dari hasil jawaban mahasiswa terhadap 4 soal mekanika fluida yang diberikan dan wawancara yang kemudian dianalisis dengan rubrik identifikasi strategi pemecahan masalah (epistemic game). Hasil analisis tes pertama menunjukkan strategi pemecahan masalah yang digunakan dalam menyelesaikan masalah adalah mapping mathematics to meaning dengan level relational dan transliteration to mathematics dengan level multistructural. Pada tes kedua, mahasiswa menggunakan pictorial analysis dengan level extended abstract dan transliteration to mathematics dengan level relational dalam menyelesaikan masalah. Sedangkan mahasiswa menyelesaikan masalah pada tes ketiga dengan menggunakan mapping mathematics to meaning dengan level relational dan recursive plug and chug dengan level relational. Mahasiswa menggunakan recursive plug and chug dengan level relational dan transliteration to mathematics dengan level relational dalam menyelesaiakn test keempat. Strategi pemecahan masalah dari penelitian ini nantinya dapat digunakan untuk menentukan strategi atau model pembelajaran yang sesuai dengan pembelajaran konsep materi.
\end{abstract}

Kata Kunci : Strategi Pemecahan Masalah, Mekanika Fluida, Taksonomi SOLO

\begin{abstract}
The main of this study is to determine the students' epistemic game of high and moderate physics-capable students in solving fluid mechanics problems.this study is a qualitative research. The participants are students learn fluid mechanics courses. The data collection of this study used interview, fluid mechanics test and physics understanding test. The physics understanding test is used to classify the physics-capable students. While epistemic game is determined by the result of students' answer of fluid mechanics test. The results of the analysis of the first test show that the epistemic game used to solve the problem is mapping mathematics to meaning with a relational level and transliteration to mathematics with a multistructural level. In the second test, students use pictorial analysis with an extended abstract level and transliteration to mathematics with a relational level in solving problems. Meanwhile, students solve problems in the third test by using mathematics to meaning mapping with a relational level and recursive plug and chug with a relational level. Students use recursive plug and chug with a relational level and transliteration to mathematics with a relational level in completing the fourth test. The problem-solving strategy of this study can later be used to determine a strategy or learning model that is suitable for learning material concepts.
\end{abstract}

Keywords : Epistemic Game, Students, Fluid Mechanics 


\section{A. PENDAHULUAN}

Orientasi pendidikan telah bergeser menyiapkan mahasiswa untuk siap menghadapi dan mengatasi dunia kerja. Pengetahuan mahasiswa dengan struktur teori fundamental gagal dalam mengembangkan keterampilan dan kemampuan praktik yang sangat dibutuhkan di dunia kerja. Dalam menghadapi dunia kerja di masa yang akan datang, mahasiswa tidak hanya dibekali pemahaman konsep akan tetapi juga kemampuan berpikir dalam menggunakan pengetahuannya dalam memecahkan masalah. Semakin beragamnya kebutuhan di dunia kerja maka dibutuhkan semakin banyak lulusan yang mampu memecahkan masalah. Salah satu konsep yang perlu dikuasai mahasiswa teknik dalam mempersiapkan diri di dunia kerja adalah pemahaman konsep fluida. Proses pembelajaran fluida yang ada selama ini masih bersifat informatif dan kurang memberikan pengalaman nyata pada mahasiswa. Salah satu hasil studi yang telah dilakukan oleh Fathiah,dkk (Fathiah et al., 2015) menunjukkan bahwa pembelajaran fisika cenderung bersifat informatif dan kurang memfasilitasi mahasiswa dalam menghubungkan konsep yang dipelajari dengan fenomena yang terkait. Mahasiswa pada akhirnya kurang memiliki pengalaman belajar langsung dengan wujud nyata sifat fluida serta mempengaruhi pemahaman mahasiswa tersebut.

Proses pemahaman mahasiswa tergantung pada keterlibatan aktif mahasiswa dalam kegiatan belajar. Hal ini dapat ditunjukkan dapat ditunjukkan pada perkembangan dari kerja praktik dan beberapa momen penilaian yang memiliki dampak positif pada cara mereka fokus pada konsep dan mengikuti matakuliah yang diajarkan, memberikan pengetahuan tentang bidang yang diteliti, mendorong kolaborasi bekerja dan merangsang keingintahuan mahasiswa (Sena-Esteves et al., 2019). Momen penilaian membantu dan merangsang pembentukan pengetahuan mahasiswa, tetapi mahasiswa masih mengalami kesulitan dalam menghubungkan antar konsep yang diperoleh. Kesulitan juga terlihat pada proses belajar-mengajar mekanika fluida dimana konsep mekanika fluida dinilai memiliki karakteristik yang sulit dan tidak menarik banyak mahasiswa teknik. Sehingga pendidik harus merenungkan potensi kurangnya minat atau partisipasi dan kesulitan memahami konsep atau dengan ekspresi lisan dan tulisan mahasiswa di kelas. Hal ini dapat diasumsikan bahwa ada kemungkinan bahwa strategi pengajaran selama ini tidak sesuai dengan gaya belajar sebagian besar mahasiswa, yang tidak memberikan motivasi dan asimilasi yang positif untuk mahasiswa selama proses belajarmengajar.

Kesulitan yang paling kritis muncul dari ketidakmampuan mahasiswa dalam membangun hubungan antara kinematika dan dinamika fluida bergerak, dan dari kekurangannya pemahaman tentang bagaimana berbagai wilayah sistem berinteraksi (Suarez et al., 2017). Hal ini meyakinkan bahwa memahami kesulitan mahasiswa adalah langkah yang perlu untuk diperbaiki di bidang sains dan teknik. Tidak hanya itu, kualitas pengetahuan mahasiswa menentukan kualitas dari apa yang telah dirancang, produksi atau memahami konsep yang mempertimbangkan dan mengartikulasikan asumsi dalam pemecahan masalah (Adair \& Jaeger, 2016). Kualitas pengetahuan masalah mahasiswa dapat 
ditingkatkan melalui pembelajaran produktif dengan aktvitas yang menarik bagi semua gaya belajar. Pada saat yang sama, pembelaaran ini harus memotivasi mahasiswa dalam menyoroti konsep-konsep penting, menggunakan contoh-contoh sederhana sambil mengesampingkan metode dan prosedur usang yang tidak lagi digunakan. Menurut pendapat banyak ilmuwan, kualitas pengetahuan dan pemahaman mahasiswa diperlukan dalam menyelesaikan tugas-tugas kognitif untuk memecahkan masalah secara sistematis (Guseinova, 2018).

Hubungan pemahaman mahasiswa tentang pemecahan masalah ditunjukkan oleh strategi dan pengembangan pengetahuan mahasiswa. Pemecahan masalah merupakan bagian inheren dari bidang teknik. Sedangkan strategi yang tepat difokuskan pada pengajaran suatu konsep misalnya mekanika fluida untuk lebih memotivasi mahasiswa (Gamez-montero et al., 2015). Strategi ini harus memperhitungkan keaktifan mahasiswa dalam berpartisipasi, di mana mahasiswa bukan hanya penerima informasi secara pasif. Strategi pemecahan masalah tidak lepas dari proses berpikir mahasiswa dalam menyelesaikan masalah. Taksonomi SOLO merupakan alat yang digunakan untuk mengkategorikan berpikir mahasiswa. Hal ini berdasarkan penelitian yang telah dilakukan oleh Kamol (Kamol \& Har, 2010) yaitu mengenai kerangka berpikir yang dikarakterisasikan berdasarkan taksonomi SOLO. Kerangka taksonomi SOLO mengklasifikasikan kemampuan proses berpikir terhadap sebuah permasalahan. Hal ini mengklasifikasikan tingkat respons untuk pengembangan proses berpikir.

\section{B. METODE}

Penelitian ini adalah penelitian kualitatif (Miles \& Huberman, 1994). Wawancara, tes mekanika fluida dan tes fisika dasar digunakan untuk mengumpulkan data kualitatif. Hal ini untuk menentukan epistemic game mahasiswa berkemampuan fisika dan sedang menurut taksonomi SOLO dalam menyelesaikan tes mekanika fluida. Epistemic game menurut taksonomi SOLO ditentukan dari hasil jawaban mahasiswa terhadap 4 soal mekanika fluida yang diberikan yang kemudian dianalisis dengan rubrik identifikasi epistemic game dan rubrik taksonomi SOLO. Subjek peneltian ini adalah mahasiswa yang mempelajari mekanika fluida (73 mahasiswa Teknik Mesin) Fakultas Teknik Universitas Nusantara PGRI Kediri. Mahasiswa yang memiliki kemampuan fisika tinggi dan sedang (6 mahasiswa berkemampuan sedang dan 67 mahasiswa berkemampuan tinggi) berdasarkan hasil tes kemampuan fisika mereka. Adapun Teknik analisis data dalam penelitian ini (Miles \& Huberman, 1994) yaitu reduksi data, penyajian data dan penarikan kesimpulan.

\section{HASIL DAN PEMBAHASAN}

Mahasiswa berkemampuan fisika tinggi terdiri atas 67 mahasiswa. sedangkan mahasiswa berkemampuan fisika sedang sebanyak 6 mahasiswa. Sebaran strategi pemecahan masalah mekanika fluida mahasiswa berkemampuan tinggi dan sedang menurut Taksonomi SOLO disajikan pada tabel 1. 
Tabel 1. Sebaran Strategi Pemecahan Masalah Mekanika Fluida Mahasiswa Berkemampuan Tinggi dan Sedang menurut Taksonomi SOLO.

\begin{tabular}{|c|c|c|c|c|c|c|c|c|}
\hline \multirow[t]{2}{*}{ Kode } & \multicolumn{4}{|c|}{ EPISTEMIC GAME } & \multicolumn{4}{|c|}{ LEVEL TAKSONOMI SOLO } \\
\hline & 1 & 2 & 3 & 4 & 1 & 2 & 3 & 4 \\
\hline M001 & MMM2 & TM & RPC & $\mathrm{RPC}$ & $\mathrm{R}$ & $\mathrm{R}$ & $\mathrm{R}$ & $\mathrm{R}$ \\
\hline M002 & MMM2 & TM & RPC & RPC & $\mathrm{R}$ & $\mathrm{R}$ & $\mathrm{R}$ & $\mathrm{R}$ \\
\hline M003 & MMM2 & PA & MMM2 & $\mathrm{RPC}$ & $\mathrm{R}$ & EA & $\mathrm{R}$ & $\mathrm{R}$ \\
\hline M005 & TM & TM & RPC & RPC & $\mathrm{M}$ & $\mathrm{R}$ & $\mathrm{R}$ & $\mathrm{R}$ \\
\hline M006 & TM & TM & MMM2 & RPC & $\mathrm{M}$ & $\mathrm{R}$ & $\mathrm{R}$ & $\mathrm{R}$ \\
\hline M007 & MMM2 & TM & RPC & $\mathrm{RPC}$ & $\mathrm{R}$ & $\mathrm{R}$ & $\mathrm{R}$ & $\mathrm{R}$ \\
\hline M008 & MMM2 & TM & RPC & RPC & $\mathrm{R}$ & $\mathrm{R}$ & $\mathrm{R}$ & $\mathrm{R}$ \\
\hline M010 & MMM2 & TM & RPC & RPC & $\mathrm{R}$ & $\mathrm{R}$ & $\mathrm{R}$ & $\mathrm{R}$ \\
\hline M011 & MMM2 & PA & RPC & RPC & $\mathrm{R}$ & EA & $\mathrm{R}$ & $\mathrm{R}$ \\
\hline M012 & TM & TM & RPC & RPC & M & $\mathrm{R}$ & $\mathrm{R}$ & $\mathrm{R}$ \\
\hline M016 & MMM2 & TM & RPC & RPC & $\mathrm{R}$ & $\mathrm{R}$ & $\mathrm{R}$ & $\mathrm{R}$ \\
\hline M018 & MMM2 & TM & RPC & RPC & $\mathrm{R}$ & $\mathrm{R}$ & $\mathrm{R}$ & $\mathrm{R}$ \\
\hline M019 & TM & $\mathrm{TM}$ & RPC & RPC & M & $\mathrm{R}$ & $\mathrm{R}$ & $\mathrm{R}$ \\
\hline M020 & MMM2 & TM & RPC & RPC & $\mathrm{R}$ & $\mathrm{R}$ & $\mathrm{R}$ & $\mathrm{R}$ \\
\hline M021 & MMM2 & TM & RPC & RPC & $\mathrm{R}$ & $\mathrm{R}$ & $\mathrm{R}$ & $\mathrm{R}$ \\
\hline M022 & MMM2 & TM & RPC & RPC & $\mathrm{R}$ & $\mathrm{R}$ & $\mathrm{R}$ & $\mathrm{R}$ \\
\hline M028 & $\mathrm{TM}$ & TM & RPC & RPC & M & $\mathrm{R}$ & $\mathrm{R}$ & $\mathrm{R}$ \\
\hline M029 & MMM2 & TM & RPC & RPC & $\mathrm{R}$ & $\mathrm{R}$ & $\mathrm{R}$ & $\mathrm{R}$ \\
\hline M030 & TM & TM & RPC & RPC & $\mathrm{M}$ & $\mathrm{R}$ & $\mathrm{R}$ & $\mathrm{R}$ \\
\hline M031 & TM & TM & RPC & RPC & $\mathrm{M}$ & $\mathrm{R}$ & $\mathrm{R}$ & $\mathrm{R}$ \\
\hline M032 & MMM2 & TM & RPC & RPC & $\mathrm{R}$ & $\mathrm{R}$ & $\mathrm{R}$ & $\mathrm{R}$ \\
\hline M034 & MMM2 & TM & RPC & RPC & $\mathrm{R}$ & $\mathrm{R}$ & $\mathrm{R}$ & $\mathrm{R}$ \\
\hline M035 & MMM2 & TM & RPC & RPC & $\mathrm{R}$ & $\mathrm{R}$ & $\mathrm{R}$ & $\mathrm{R}$ \\
\hline M036 & TM & TM & RPC & RPC & M & $\mathrm{R}$ & $\mathrm{R}$ & $\mathrm{R}$ \\
\hline M037 & MMM2 & PA & RPC & RPC & $\mathrm{R}$ & EA & $\mathrm{R}$ & $\mathrm{R}$ \\
\hline M038 & MMM2 & PA & RPC & RPC & $\mathrm{R}$ & EA & $\mathrm{R}$ & $\mathrm{R}$ \\
\hline M039 & MMM2 & TM & RPC & RPC & $\mathrm{R}$ & $\mathrm{R}$ & $\mathrm{R}$ & $\mathrm{R}$ \\
\hline M040 & MMM2 & PA & RPC & RPC & $\mathrm{R}$ & EA & $\mathrm{R}$ & $\mathrm{R}$ \\
\hline M042 & MMM2 & TM & RPC & RPC & $\mathrm{R}$ & $\mathrm{R}$ & $\mathrm{R}$ & $\mathrm{R}$ \\
\hline M043 & MMM2 & PA & RPC & RPC & $\mathrm{R}$ & EA & $\mathrm{R}$ & $\mathrm{R}$ \\
\hline M044 & MMM2 & TM & RPC & RPC & $\mathrm{R}$ & $\mathrm{R}$ & $\mathrm{R}$ & $\mathrm{R}$ \\
\hline M045 & MMM2 & PA & RPC & RPC & $\mathrm{R}$ & EA & $\mathrm{R}$ & $\mathrm{R}$ \\
\hline M047 & MMM2 & PA & RPC & RPC & $\mathrm{R}$ & EA & $\mathrm{R}$ & $\mathrm{R}$ \\
\hline M048 & MMM2 & PA & RPC & RPC & $\mathrm{R}$ & EA & $\mathrm{R}$ & $\mathrm{R}$ \\
\hline M050 & MMM2 & PA & RPC & RPC & $\mathrm{R}$ & EA & $\mathrm{R}$ & $\mathrm{R}$ \\
\hline M053 & TM & TM & RPC & RPC & M & $\mathrm{R}$ & $\mathrm{R}$ & $\mathrm{R}$ \\
\hline M054 & $\mathrm{TM}$ & TM & MMM2 & RPC & $\mathrm{M}$ & $\mathrm{R}$ & $\mathrm{R}$ & $\mathrm{R}$ \\
\hline M055 & MMM2 & $\mathrm{TM}$ & RPC & RPC & $\mathrm{R}$ & $\mathrm{R}$ & $\mathrm{R}$ & $\mathrm{R}$ \\
\hline M056 & $\mathrm{TM}$ & TM & RPC & RPC & M & $\mathrm{R}$ & $\mathrm{R}$ & $\mathrm{R}$ \\
\hline M057 & $\mathrm{TM}$ & TM & RPC & RPC & M & $\mathrm{R}$ & $\mathrm{R}$ & $\mathrm{R}$ \\
\hline M058 & MMM2 & TM & RPC & RPC & $\mathrm{R}$ & $\mathrm{R}$ & $\mathrm{R}$ & $\mathrm{R}$ \\
\hline M059 & MMM2 & TM & RPC & TM & $\mathrm{R}$ & $\mathrm{R}$ & $\mathrm{R}$ & $\mathrm{R}$ \\
\hline M060 & TM & TM & RPC & RPC & $\mathrm{M}$ & $\mathrm{R}$ & $\mathrm{R}$ & $\mathrm{R}$ \\
\hline M062 & MMM2 & TM & RPC & RPC & $\mathrm{R}$ & $\mathrm{R}$ & $\mathrm{R}$ & $\mathrm{R}$ \\
\hline M063 & MMM2 & PA & RPC & RPC & $\mathrm{R}$ & EA & $\mathrm{R}$ & $\mathrm{R}$ \\
\hline M064 & MMM2 & TM & RPC & RPC & $\mathrm{R}$ & $\mathrm{R}$ & $\mathrm{R}$ & $\mathrm{R}$ \\
\hline M066 & $\mathrm{TM}$ & $\mathrm{TM}$ & RPC & RPC & M & $\mathrm{R}$ & $\mathrm{R}$ & $\mathrm{R}$ \\
\hline M070 & MMM2 & TM & RPC & RPC & $\mathrm{R}$ & $\mathrm{R}$ & $\mathrm{R}$ & $\mathrm{R}$ \\
\hline
\end{tabular}




\begin{tabular}{|c|c|c|c|c|c|c|c|c|}
\hline M071 & MMM2 & PA & RPC & RPC & $\mathrm{R}$ & EA & $\mathrm{R}$ & $\mathrm{R}$ \\
\hline M072 & MMM2 & PA & RPC & RPC & $\mathrm{R}$ & EA & $\mathrm{R}$ & $\mathrm{R}$ \\
\hline M073 & MMM2 & $\mathrm{TM}$ & RPC & RPC & $\mathrm{R}$ & $\mathrm{R}$ & $\mathrm{R}$ & $\mathrm{R}$ \\
\hline M076 & MMM2 & PA & RPC & RPC & $\mathrm{R}$ & EA & $\mathrm{R}$ & $\mathrm{R}$ \\
\hline M077 & MMM2 & PA & RPC & RPC & $\mathrm{R}$ & EA & $\mathrm{R}$ & $\mathrm{R}$ \\
\hline M078 & MMM2 & PA & RPC & RPC & $\mathrm{R}$ & EA & $\mathrm{R}$ & $\mathrm{R}$ \\
\hline M080 & TM & TM & RPC & RPC & M & $\mathrm{R}$ & $\mathrm{R}$ & $\mathrm{R}$ \\
\hline M081 & TM & $\mathrm{TM}$ & MMM2 & RPC & M & $\mathrm{R}$ & $\mathrm{R}$ & $\mathrm{R}$ \\
\hline M082 & MMM2 & $\mathrm{TM}$ & RPC & RPC & $\mathrm{R}$ & $\mathrm{R}$ & $\mathrm{R}$ & $\mathrm{R}$ \\
\hline M083 & MMM2 & $\mathrm{PA}$ & RPC & RPC & $\mathrm{R}$ & EA & $\mathrm{R}$ & $\mathrm{R}$ \\
\hline M084 & MMM2 & $\mathrm{TM}$ & RPC & RPC & $\mathrm{R}$ & $\mathrm{R}$ & $\mathrm{R}$ & $\mathrm{R}$ \\
\hline M085 & MMM2 & PA & RPC & RPC & $\mathrm{R}$ & EA & $\mathrm{R}$ & $\mathrm{R}$ \\
\hline M087 & MMM2 & $\mathrm{TM}$ & RPC & RPC & $\mathrm{R}$ & $\mathrm{R}$ & $\mathrm{R}$ & $\mathrm{R}$ \\
\hline M089 & MMM2 & TM & RPC & $\mathrm{TM}$ & $\mathrm{R}$ & $\mathrm{R}$ & $\mathrm{R}$ & $\mathrm{R}$ \\
\hline M091 & MMM2 & $\mathrm{TM}$ & RPC & RPC & $\mathrm{R}$ & $\mathrm{R}$ & $\mathrm{R}$ & $\mathrm{R}$ \\
\hline M092 & MMM2 & $\mathrm{TM}$ & RPC & RPC & $\mathrm{R}$ & $\mathrm{R}$ & $\mathrm{R}$ & $\mathrm{R}$ \\
\hline M093 & MMM2 & $\mathrm{PA}$ & RPC & RPC & $\mathrm{R}$ & EA & $\mathrm{R}$ & $\mathrm{R}$ \\
\hline M095 & TM & TM & RPC & RPC & M & $\mathrm{R}$ & $\mathrm{R}$ & $\mathrm{R}$ \\
\hline M097 & MMM2 & $\mathrm{TM}$ & RPC & $\mathrm{TM}$ & $\mathrm{R}$ & $\mathrm{R}$ & $\mathrm{R}$ & $\mathrm{R}$ \\
\hline M99 & MMM2 & PA & RPC & RPC & $\mathrm{R}$ & EA & $\mathrm{R}$ & $\mathrm{R}$ \\
\hline M100 & MMM2 & $\mathrm{TM}$ & RPC & RPC & $\mathrm{R}$ & $\mathrm{R}$ & $\mathrm{R}$ & $\mathrm{R}$ \\
\hline M101 & MMM2 & $\mathrm{TM}$ & RPC & RPC & $\mathrm{R}$ & $\mathrm{R}$ & $\mathrm{R}$ & $\mathrm{R}$ \\
\hline M102 & MMM2 & $\mathrm{TM}$ & RPC & RPC & $\mathrm{R}$ & $\mathrm{R}$ & $\mathrm{R}$ & $\mathrm{R}$ \\
\hline M107 & MMM2 & $\mathrm{TM}$ & RPC & RPC & $\mathrm{R}$ & $\mathrm{R}$ & $\mathrm{R}$ & $\mathrm{R}$ \\
\hline M112 & MMM2 & TM & RPC & RPC & $\mathrm{R}$ & $\mathrm{R}$ & $\mathrm{R}$ & $\mathrm{R}$ \\
\hline
\end{tabular}

\section{Keterangan}

Kode M001 : Mahasiswa 1

Kode M002 : Mahasiswa 2, dst.

Keterangan Epistemic Game:

MMM1: Mapping Meaning to Mathematics

MMM2: Mapping Mathematics to Meaning

PM : Physical Mechanism

PA : Pictorial Analysis

RPC : Recursive Plug and Chug

TM : Transliteration to Mathematics

Keterangan Level Taksonomi SOLO:
P : Prestructural
$\mathrm{U} \quad$ : Unistructural
$\mathrm{M} \quad$ : Multistructural
$\mathrm{R} \quad$ : Relational
EA : Extended Abstract

\begin{tabular}{|l|l|}
\hline Kemampuan & Tinggi \\
\hline Kemampuan & Sedang \\
\hline
\end{tabular}


Tabel 1 menunjukkan sebaran strategi pemecahan masalah mahasiswa menurut taksonomi SOLO dalam menyelesaikan masalah mekanika fluida. M diikuti angka dalam tabel merupakan kode mahasiswa yang menunjukkan karakteristik mahasiswa. Sedangkan strategi pemacahan masalah mahasiswa berkemampuan tinggi dan rendah adalah mapping mathematics to meaning (MMM2), transliteration to mathematics (TM), pictorial analysis (PA), recursive plug and chug (RPC). Dan level taksonomi SOLO mahasiswa dalam penelitian ini menunjukkah mahasiswa menggunakan relational (R), multistructural (M) dan extended abstract (EA) dalam menyelesaikan masalah mekanika fluida.

Strategi pemecahan masalah digunakan mahasiswa berkemampuan fisika tinggi dan rendah menurut taksnomi SOLO dalam menyelesaikan masalah mekanika fluida dan dijabarkan sebagai berikut: pada test pertama, mahasiswa menggunakan mapping mathematics to meaning dengan level relational dan transliteration to mathematics dengan level multistructural. Mapping mathematics to meaning dengan level relational digunakan oleh mahasiswa dalam mengidentifikasi dan menggabungkan antar konsep fluida, menemukan persamaan dalam menyelesaikan permalasahan serta mengevaluasi permasalahan fluida. Dalam hal ini, mahasiswa menggunakan dan menggabungkan semua konsep dan data yang terdapat pada test pertama. Sedangkan mahasiswa yang menggunakan transliteration to mathematics dengan level multistructural melakukan identifikasi besaran, menemukan pola solusi test pertama, memetakan besaran dan mengevaluasi pemetaan masalah test pertama. Hal ini menunjukkan mahasiswa menggunakan dan memberi tanggapan beberapa data serta tidak dapat mengghubungkan antar konsep/data yang tertuang dalam test pertama.

Hasil analisis ini menunjukkan mahasiswa memecahkan tes dengan mengikuti proses kognisi dalam memecahkan masalah. Pembentukan pemahaman mahasiswa dan pemberian informasi guna memecahkan masalah tergantung dari tujuan pendidikan dalam mengartikulasikan pemilihan dan desain masalah (Teodorescu et al., 2013). Mahasiswa mengembangkan cerita konseptual yang berhubungan dengan persamaan fisika dalam strategi mapping mathematics to meaning (Tuminaro \& Redish, 2007). Mahasiswa mulai dengan sebuah persamaan fisika dan kemudian mengembangkan cerita konseptual. Mahasiswa merespon beberapa data yang terdapat dalam masalah yang diberikan tanpa menghubungkan antar data pada level multistructural. Mahasiswa memberikan respon dan berfokus pada beberapa data yang relevan dengan masalah yang diberikan, serta data masih tidak terintegrasi (Lian \& Yew, 2012).

Pada test kedua, mahasiswa menggunakan pictorial analysis dengan level extended abstract dan transliteration to mathematics dengan level relational. Pictorial analysis dengan level extended abstract digunakan oleh mahasiswa dalam menentukan konsep, menggambrakna proses yang terjadi dalam aliran sebuah tangki, menjelaskan permasalahan secara konseptual dan merepresentasikan permasalahan. Hal ini menunjukkan mahasiswa menerapkan persamaan yang berhubungan dengan permasalahan, menemukan prinsip umum dari data dan menerapkannya dalam menyelesaikan permasalahan, serta memberikan tanggapan dengan menghubungkan antara konsep/data yang terdapat 
dalam test kedua. Sementara itu, mahasiswa menggunakan transliteration to mathematics dengan level relational melakukan identifikasi besaran, menemukan pola solusi test pertama, memetakan besaran dan mengevaluasi pemetaan masalah test mekanika fluida kedua. Hal ini menunjukkan mahasiswa menggunakan dan menggabungkan semua konsep dan data yang terdapat pada test pertama.

Pemahaman yang terorganisir dapat menganalisis secara kualitatif dan merencanakan solusi yang memungkinkan untuk memantau kemajuan kemampuan mahasiswa (Ogilvie, 2009). Hal ini menunjukkan bahwa strategi pemecahan masalah seperti transliteration to mathematics menggunakan contoh pekerjaan untuk menghasilkan solusi tanpa mengembangkan pemahaman konseptual. Mahasiswa menghitung secara bertahap, menuliskan simbol hanya untuk menentukan penyelesaian masalah (Tuminaro \& Redish, 2007). Berdasarkan respons yang diberikan mahasiswa, mahasiswa cenderung ke level relational. Pada level relational, semua aspek informasi yang diberikan satu sama lain diintegrasikan menjadi struktur yang koheren (Jamil, 2017). Selain itu, mahasiswa dapat menghubungkan antar fakta dan membangun prinsip/teori dalam menyelesaikan masalah yang diberikan dalam waktu singkat (Appulembang, 2017).

Epistemic game menurut taksonomi SOLO yang digunakan mahasiswa pada test ketiga antara lain adalah mapping mathematics to meaning dengan level relational dan recursive plug and chug dengan level relational. Mahasiswa menggunakan mapping mathematics to meaning dengan level relational dalam mengidentifikasi dan menggabungkan antar konsep fluida, menemukan persamaan dalam menyelesaikan permalasahan serta mengevaluasi permasalahan fluida. Dalam hal ini mahasiswa menggunakan dan menggabungkan semua konsep dan data yang terdapat pada test ketiga. Sedangkan mahasiswa yang menggunakan recursive plug and chug dengan level relational melakukan mengidentifikasi dan menghitung besaran, menemukan persamaan yang berhubungan dengan permasalahan, mengidentifikasi dan menentukan besaran baru dalam menyelesaikan masalah mekanika fluida. Hal ini menunjukkan menggunakan dan menggabungkan semua konsep dan data.

Hasil penelitian tersebut dapat dijelaskan bahwa mahasiswa menggunakan beberapa strategi pemecahan masalah. Hal ini sesuai dengan penelitian (Tuminaro \& Redish, 2007) yang menyatakan bahwa sumber spesifik dan strategi bukanlah satu-satunya mahasiswa gunakan atau mainkan. Berdasarkan hasil penelitian (Tuminaro \& Redish, 2007), model kognitif dalam pemecahan masalah (strategi pemecahan masalah) membantu meningkatkan pemahaman tentang yang dipelajari mahasiswa.

Test keempat yang telah diselesaikan mahasiswa menggunakan recursive plug and chug dengan level relational dan transliteration to mathematics dengan level relational. Recursive plug and chug dengan level relational digunakan oleh mahasiswa dalam mengidentifikasi dan menghitung besaran, menemukan persamaan yang berhubungan dengan permasalahan, mengidentifikasi dan menentukan besaran baru dalam menyelesaikan masalah mekanika fluida. Dalam hal ini mahasiswa menggunakan dan menggabungkan semua konsep dan data. Sedangkan transliteration to mathematics 
dengan level relational yang digunakan oleh mahasiswa mengidentifikasi besaran, menemukan pola solusi test pertama, memetakan besaran dan mengevaluasi pemetaan masalah test mekanika fluida. Hal ini menunjukkan mahasiswa menggunakan dan menggabungkan semua konsep dan data pada test keempat.

Mahasiswa menggunakan recursive plug and chug dalam menyelesaikan masalah. Pada pelaksanaan recursive plug and chug, mahasiswa tidak mengidentifikasi dan memasang besaran ke dalam persamaan. Bentuk epistemik dari recursive plug and chug identik dengan mapping meaning to mathematics. Recursive plug and chug mengandalkan pemahaman sintaksi dari simbol fisika tanpa mencoba memahami simbol secara konseptual (Tuminaro, 2004).

\section{SIMPULAN}

Kesimpulan dari penelitian ini adalah hasil analisis yang berupa strategi pemecahan mahasiswa berkemampuan fisika sedang menurut taksonomi SOLO untuk menyelesaikan masalah mekanika fluida. Strategi pemecahan masalah mahasiswa berkemampuan fisika tinggi dan sedang yaitu mapping mathematics to meaning, transliteration to meaning, recursive plug and chug, dan pictorial analysis dalam menyelesaikan soal mekanika fluida. Sedangkan menyelesaikan dengan level taksonomi SOLO yang berbeda-beda yaitu relational, multistructural dan extended abstract.

Strategi pemecahan masalah menurut taksonomi SOLO dari penelitian ini dapat digunakan untuk menentukan strategi atau model pembelajaran yang sesuai dengan pembelajaran konsep materi. Penelitian ini hanya terbatas strategi pemecahan masalah menurut taksonomi SOLO pada konsep materi mekanika fluida. Sehingga dapat dilakukan penelitian lanjutan pada konsep materi yang lain dan juga dapat diterapkan model pembelajaran untuk menunjang pembelajaran konsep materi tersebut.

\section{DAFTAR RUJUKAN}

Adair, D., \& Jaeger, M. (2016). Incorporating Critical Thinking into an Engineering Undergraduate Learning Environment. International Journal of Higher Education, 5(2), 23-39. https://doi.org/10.5430/ijhe.v5n2p23

Appulembang, O. D. (2017). Profil Pemecahan Masalah Aljabar Berpandu pada Taksonomi Solo Ditinjau dari Gaya Kognitif Konseptual Tempo Siswa SMA Negeri 1 Makale Tana Toraja. Journal of Language, Literature, Culture, and Education, 13(2), 133-149. https://ojs.uph.edu/index.php/PJI/article/download/336/pdf

Fathiah, F., Kaniawati, I., \& Utari, S. (2015). Analisis Didaktik Pembelajaran yang Dapat Meningkatkan Korelasi antara Pemahaman Konsep dan Kemampuan Pemecahan Masalah Siswa SMA pada Materi Fluida Dinamis. Jurnal Penelitian \& Pengembangan Pendidikan Fisika, 1(1), 111-118. https://doi.org/10.21009/1.01116

Gamez-montero, P. J., Raush, G., Domènech, L., Castlla, R., García-vílchez, M., \& Carbó, A. (2015). 
Fluid Mechanics Courses in Undergraduate Engineering Programs. 5(1), 15-30.

Guseinova, E. E. (2018). Organizational and pedagogical conditions for the development of professional competencies in the technical students' individual work through the example of studying the discipline «Hydraulics and fluid mechanics». European Journal of Contemporary Education, 7(1), 118-126. https://doi.org/10.13187/ejced.2018.1.118

Jamil, A. F. (2017). Peningkatan Level Berpikir Aljabar Siswa Berdasarkan Taksonomi SOLO pada Materi Persamaan Linier melalui Pemberian Scaffolding. Jurnal Ilmiah Mandala Education, 3(1), 175-183. http://ejournal.mandalanursa.org/index.php/JIME/article/view/34

Kamol, N., \& Har, Y. B. (2010). Upper Primary School Students' Algebraic Thinking. Proceedings of the 33rd Annual Conference of the Mathematics Education Research Group of Australasia, July, 3-7. https://files.eric.ed.gov/fulltext/ED520911.pdf

Lian, L. H., \& Yew, W. T. (2012). Assessing algebraic solving ability: A theoretical framework. International Education Studies, 5(6), 177-188. https://doi.org/10.5539/ies.v5n6p177

Miles, M. B., \& Huberman, A. M. (1994). Qualitative Data Analysis. In R. Holland (Ed.), SAGE Publications (Second). SAGE Publications.

Ogilvie, C. A. (2009). Changes in students' problem-solving strategies in a course that includes contextrich, multifaceted problems. Physical Review Special Topics - Physics Education Research, 5(2), 1-14. https://doi.org/10.1103/PhysRevSTPER.5.020102

Sena-Esteves, T., Morais, C., Guedes, A., Pereira, I. B., Ribeiro, M. M., Soares, F., \& Leão, C. P. (2019). Student's perceptions regarding assessment changes in a fluid mechanics course. Education Sciences, 9(2), 1-19. https://doi.org/10.3390/educsci9020152

Suarez, A., Kahan, S., Zavala, G., \& Marti, A. C. (2017). Students' conceptual difficulties in hydrodynamics. Physical Review Physics Education Research, 13(2), 1-12. https://doi.org/10.1103/PhysRevPhysEducRes.13.020132

Teodorescu, R. E., Bennhold, C., Feldman, G., \& Medsker, L. (2013). New approach to analyzing physics problems: A taxonomy of introductory physics problems. Physical Review Special Topics - Physics Education Research, 9(1), 1-20. https://doi.org/10.1103/PhysRevSTPER.9.010103

Tuminaro, J. (2004). A Cognitive Framework for Analyzing and Describing Introductory Students' Use and Understanding of Mathematics in Physics. In Unpublished Thesis. University of Maryland.

Tuminaro, J., \& Redish, E. F. (2007). Elements of a cognitive model of physics problem solving: Epistemic games. Physical Review Special Topics - Physics Education Research, 3(2), 1-22. https://doi.org/10.1103/PhysRevSTPER.3.020101 